\title{
Research on an Integrated Hydrostatic-Driven Electric Generator with Controllable Load for Renewable Energy Applications
}

\author{
Tao Wang ${ }^{1, *}$ and He Wang ${ }^{2}$ \\ 1 Ocean College, Zhejiang University, Zhoushan 316000, China \\ 2 College of Mechanical and Vehicle Engineering, Hunan University, Changsha 410082, China; \\ chaoqiao86@163.com \\ * Correspondence: twang001@zju.edu.cn; Tel.: +86-580-209-2306
}

Received: 11 August 2017; Accepted: 28 August 2017; Published: 30 August 2017

\begin{abstract}
A hydrostatic transmission is a promising technology in renewable energy harvesting, such as wind energy and wave energy, where the hydrostatic-driven electric generator is a key energy conversion component. By using analytical and experimental methods, this paper investigates the performance of a novel hydrostatic-driven electric generator which integrates the functions of an axial piston hydrostatic motor and a permanent magnet electric generator together. The experimental platform consists of a prototype, an adjustable hydrostatic power source, a controllable electrical load, and various sensors. Energy conversions between hydrostatic and electrical forms are evaluated under different operating velocities and control signals. Power loss distributions are presented by combining measured data and analytical calculation. Thermal experiments are implemented under both of natural and oil-forced cooling conditions and it is found that the temperature rise is much lower when the machine is cooled by hydraulic oil. The experiments validate the energy conversion efficiency, steady controllability, and cooling capability of the integrated hydrostatic-driven electric generator. The results can provide references for further efficiency optimization, dynamic control, as well as practical application.
\end{abstract}

Keywords: renewable energy harvesting; hydrostatic transmission; permanent magnet generator; structure integration

\section{Introduction}

Under the pressure of environmental pollution and fossil energy exhaustion, the worldwide request for alternatives to fossil fuels has been growing considerably during recent decades. Renewable energy has the potential to play an important role in providing energy with sustainability, driving a rapid improvement of energy exploiting technologies [1]. Among them, the hydrostatic transmission is a promising technology in renewable energy harvesting, such as wind energy and wave energy. A hydrostatic transmission system offers a fast response, maintains precise velocity under fluctuating loads, and allows controlling speed, torque, and power when required in heavy-duty applications.

In a wind power system with hydrostatic transmission, of which a typical schematic is presented in Figure 1a, a hydrostatic pump connected to a wind turbine generates a flow rate to drive a hydrostatic motor, which is coupled with an electric generator [2-4]. It allows mechanically-decoupled operation of the wind turbine and the generator over a wide range of wind speeds without the need of mechanical gearboxes. Since the generation device can be separated from the wind turbine and installed at the ground level, the system requires less maintenance and makes installation more convenient in comparison with traditional gearbox transmission systems $[5,6]$. With the help of hydrostatic 
accumulators, short-term energy storage can be achieved to capture more energy and smooth output power [7-9]. Lin et al. [10] proposed a hybrid transmission technology to reduce the displacement of the hydrostatic pump while retain the torque-stable feature of a hydrostatic transmission system. Schulte et al. [11] presented a fault-tolerant control scheme based on sliding mode and tested for hydrostatic wind power systems. Similar with wind energy, tidal current energy can also be harvested with hydrostatic transmission by replacing wind turbines with current turbines [12,13].

As to wave energy generation, the hydrokinetic energy generated by the translational movements of irregular waves can be absorbed and converted to hydrostatic energy by a hydrostatic cylinder with an oscillating buoyant body, and then electrical energy can be generated by a hydrostatic motor and an electric generator [14-17]. A typical schematic is presented in Figure 1b, where check valves rectify the flow direction and accumulators provide energy storage and boost pressure. Hydrostatic transmission employed in various kinds of wave energy conversion systems have been reviewed in [18]. Ahn et al. and Truong et al. [19,20] designed an innovative wave energy converter with a hydrostatic transmission to enhance energy extraction from wave fluctuations and adaptive control concepts are proposed to manage the system operation for high working efficiency. Hansen et al. [21] designed a discrete displacement hydrostatic power take-off system for wave energy harvesting by using multi-chambered cylinders and fast on/off valves. Penalba et al. [22,23] developed and validated a detailed model for a hydrostatic wave power system with consideration of the full dynamics of energy conversion stages from ocean waves to the power grid.

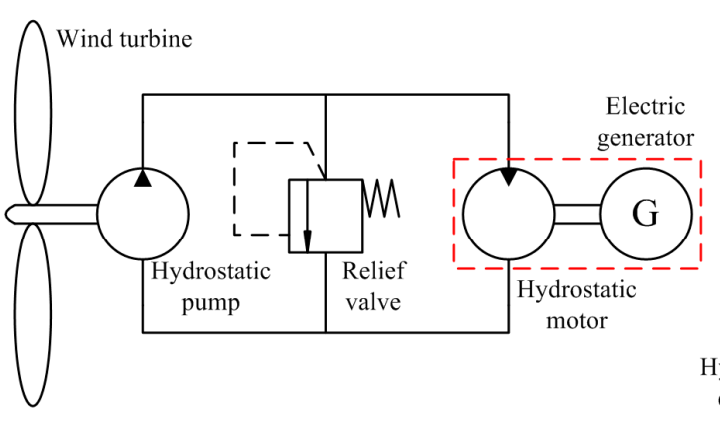

(a)

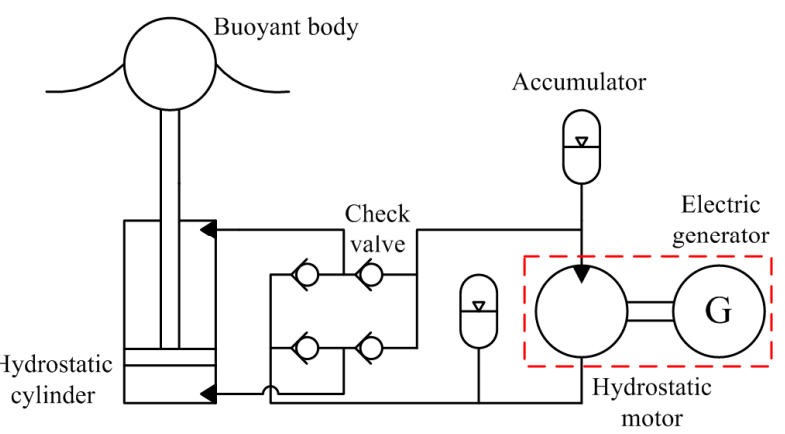

(b)

Figure 1. Schematics of renewable energy harvesting systems with hydrostatic transmission. (a) Wind energy; and (b) wave energy.

It can be noticed that in all of the aforementioned applications the hydrostatic-driven electric generator is a key energy conversion component. Additionally, this machine can also be equipped in the hydrostatic circuits of lifting booms or dampers so as to regenerate inertia or vibration energy [24-27]. However, conventional hydrostatic-driven electric generators are mostly composed of independent hydrostatic motors and coaxially coupled generators. This configuration has the disadvantages of large installation volume, additional structure for coupling, possible external leakage due to the outer shaft, and relatively high vibration and noise. Therefore, it is meaningful to develop a single component which highly integrates the functions of a hydrostatic motor and an electric generator together.

There have been several references about integrated energy conversion devices between hydrostatic and electrical forms. According to Ponomarev et al. [28,29], the shaft of a permanent magnet electric machine is directly operated on the shaft of a hydrostatic pump/motor so that a coupling can be eliminated, but the electric machine and the hydrostatic machine are still contained in separate cages. Wang et al. [30] presented the combination of a permanent magnet electric machine and an axial piston hydrostatic machine, as well as investigations on coupling effects. Ji et al. [31] proposed an integrated structure composed of an induction motor, a vane pump and an additional port-plate centrifugal pump utilized to improve suction performance. In our earlier studies, the concept of integrated hydrostatic-driven electric generator has been proposed for renewable energy harvesting 
and investigation of electromagnetic properties have been presented [32,33]. However, only initial experiments under constant load conditions were implemented, and it is not clear about the efficiency performance under a controllable load condition and the thermal performance of the integrated hydrostatic-driven electric generator.

This paper analytically and experimentally investigates an integrated hydrostatic-driven electric generator. An adjustable hydrostatic power source is utilized to simulate renewable energy and a controllable electrical load is utilized to consume generated energy. Energy conversions between hydrostatic and electrical forms are evaluated under different operating velocities and control signals. Power loss distributions are presented by combining measured data and analytical calculations. Experiments for temperature rise evaluation are implemented under both natural and oil-forced cooling conditions. The results validate the energy conversion efficiency, steady controllability, and cooling capability of the integrated hydrostatic-driven electric generator. The rest of the paper is organized as follows. Section 2 introduces the studied machine, as well as the experimental platform. Section 3 presents the energy conversion analysis and the temperature rise estimation of the studied machine. Experiments and results are presented in Section 4 and conclusions are drawn in Section 5.

\section{Machine Description and Experimental Platform}

\subsection{Structure and Principle}

A hydrostatic-driven electric generator mainly consists of a hydrostatic motor and an electric generator. The frequently used hydrostatic motors can be categorized into vane motors, gear motors, radial piston motors, swash plate axial piston motors and bent axis axial piston motors, and the frequently-used electric generators can be categorized into direct current generators, permanent magnet synchronous generators, excitation synchronous generators, asynchronous generators, and switched reluctance generators. Based on characteristic comparison, the swash plate axial piston motor and the permanent magnet synchronous generator are considered as preferable candidates for integration design because of their advantages on efficiency, power density, and structure compatibility.

Figure 2 presents the basic idea of the integration design for the hydrostatic-driven electric generator. In the conventional structure, the shafts of the swash plate axial piston motor and the permanent magnet synchronous generator are connected through a coupling. It is apparent that this bulky structure has a low volumetric power density. In the proposed structure, the hydrostatic rotor, which is also called the barrel, is installed concentrically into the inner of the electric rotor. Permanent magnets in a Halbach configuration, which has a self-shielding magnetic property, are employed to produce enough magnetic flux through the gap between stator and rotor so that there is no requirement of high permeability material serving as the rotor iron core [34]. In another word, the compound rotor just consists of the barrel and the permanent magnets. In comparison with the conventional structure, the proposed structure eliminates a cage, a coupling, a pair of bearings, a shaft, and a rotor iron core. In addition, it does not require an outer shaft for power transmission. Therefore, the integration design is beneficial to reduce the installation volume, material and cost, vibration and noise, as well as external leakage.

The principle of the studied machine is briefly illustrated as follows. The compound rotor, including the barrel and the permanent magnets, operates as hydrostatic and electrical simultaneously. On the one hand, the compound rotor will be driven to rotate by the interaction with the hydrostatic mechanism including the piston and slipper, the swash plate, and the port plate when pressurized hydraulic oil is supplied. On the other hand, according to electromagnetic theory, electromotive forces will be induced in the stator windings by the interaction between the compound rotor and the stator. Current will be generated when the windings are connected to the electrical load, and then energy conversion between hydrostatic and electrical forms will be sustained through the torque balance on the compound rotor. 

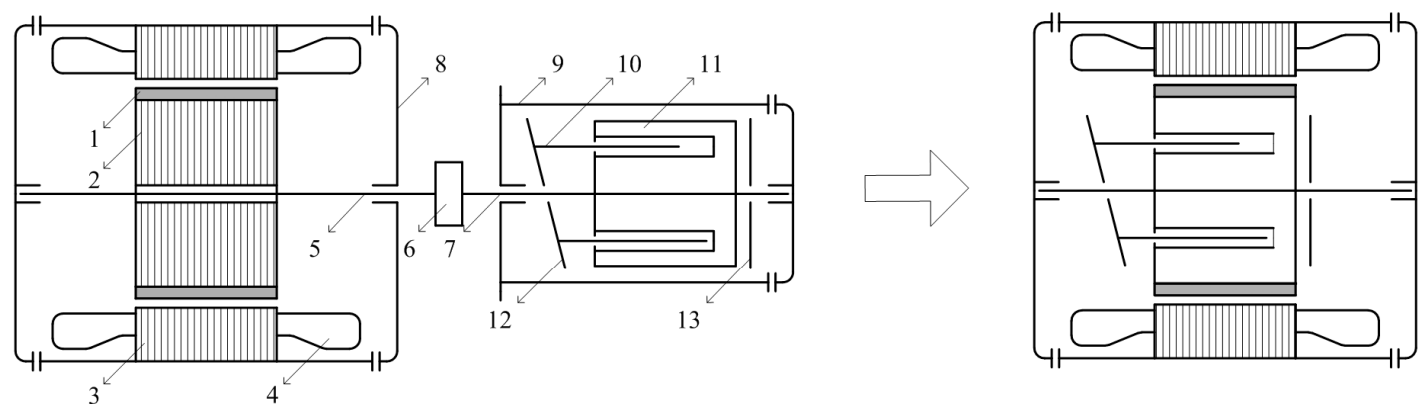

1. Permanent magnet. 2. Rotor iron core. 3. Stator iron core. 4. Winding. 5. Shaft of electric generator. 6. Coupling. 7. Shaft of hydrostatic motor. 8. Cage of electric generator. 9. Cage of hydrostatic motor. 10. Piston and slipper. 11. Barrel. 12. Swash plate. 13. Port plate.

(a)

(b)

Figure 2. Basic idea of integration design for the hydrostatic-driven electric generator. (a) Conventional structure; and (b) the proposed structure.

\subsection{Prototype}

A prototype of the integrated hydrostatic-driven electric generator is fabricated for experimental evaluation, of which the basic parameters are presented in Table 1 . The cross-sectional schematic and the photographs of the prototype are shown in Figure 3. The hydrostatic part of the prototype is with fixed displacement and the angle of the swash plate is about 10 degrees. It is noticed that the inner cage is filled with leaked hydraulic oil during operation, for there is an inevitable internal leakage from the pressurized chambers through frictional pairs. Therefore, drain ports are set in the machine cage to release leakage oil. As the compact structure gives challenge to heat dissipation and temperature rise, an oil-forced cooling approach can be realized by utilizing the two drain ports, which will be described in the next section. The prototype rotor can operate in the reverse direction by exchanging the input port and the output port. The stator windings are of a three-phase single-layer type and in star configuration.

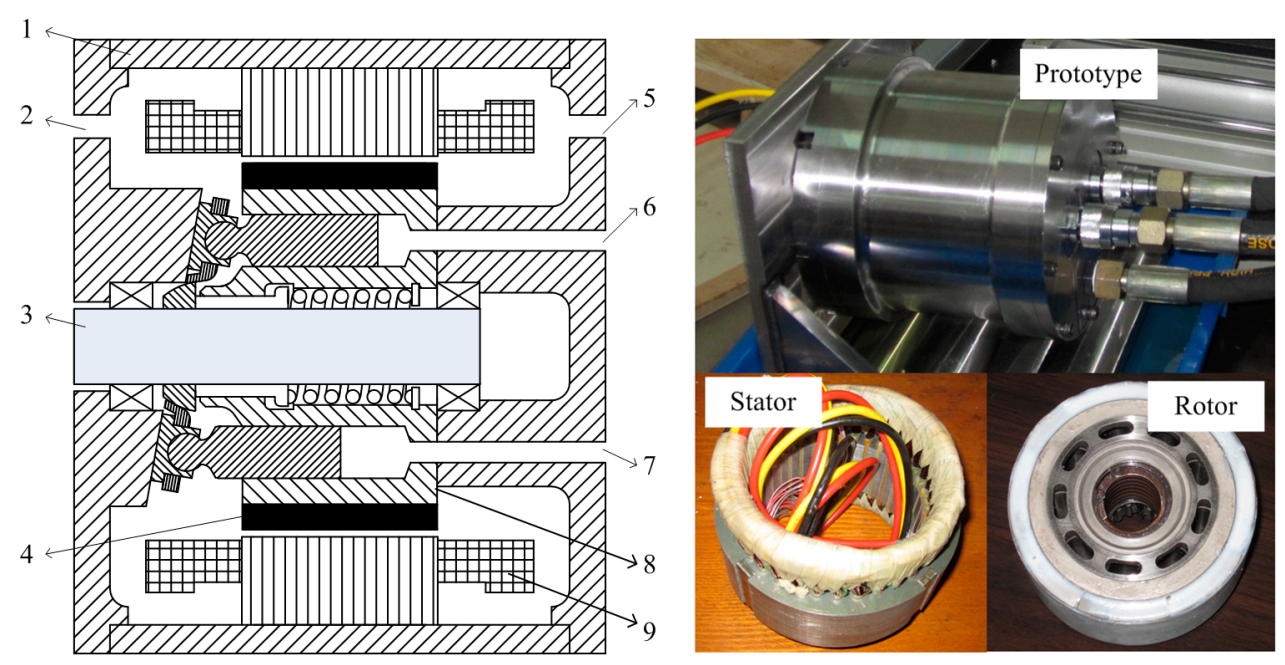

1. Cage. $2 \& 5$. Drain port. 3. Shaft. 4. Permanent magnet. 6. Output port. 7. Input port. 8. Barrel. 9. Stator.

(a)

(b)

Figure 3. Prototype of the integrated hydrostatic-driven electric generator. (a) Cross-sectional schematic; and (b) photographs.

To reduce manufacturing complexity, the Halbach permanent magnet array is composed of two-segment $\mathrm{NdFeB}$ magnets which are magnetized radially and tangentially. The permanent magnets are mounted on the barrel surface by using an oil-proof adhesive. Stator steel laminations and some 
hydrostatic parts with standard sizes are directly employed from existing products. A bracket is used to support the prototype on the experimental platform. Some techniques, including the seal of electrical terminals and the oil resistance of varnished wires, are also taken into account in the prototype fabrication.

Table 1. Basic parameters of the prototype.

\begin{tabular}{ccc}
\hline Name & Value & Unit \\
\hline Phase number & 3 & - \\
Pole pair number & 4 & - \\
Coil number per phase & 480 & - \\
Stator outer diameter & 155 & $\mathrm{~mm}$ \\
Stator inner diameter & 106 & $\mathrm{~mm}$ \\
Stator iron core axial length & 48 & $\mathrm{~mm}$ \\
Stator-rotor gap length & 2 & $\mathrm{~mm}$ \\
Permanent magnet thickness & 7.5 & $\mathrm{~mm}$ \\
Swash plate angle & 10 & degree $\left(^{\circ}\right)$ \\
Piston reference diameter & 60 & $\mathrm{~mm}$ \\
Nominal power & 2500 & $\mathrm{~W}$ \\
Nominal speed & 1500 & $\mathrm{rpm}$ \\
Nominal frequency & 100 & $\mathrm{~Hz}$ \\
Nominal input flow rate & 23 & $\mathrm{~L} / \mathrm{min}$ \\
Nominal phase current & 7 & $\mathrm{~A}$ \\
Nominal phase voltage & 127 & $\mathrm{~V}$ \\
\hline
\end{tabular}

\subsection{Experimental Platform}

An experimental platform of the integrated hydrostatic-driven electric generator is set up to investigate the energy conversion process under controllable load condition and the performance of the temperature rise. Figure 4 shows the schematic which mainly consists of a prototype, an adjustable hydrostatic power source, a controllable electrical load, and various sensors. The hydrostatic power source can provide a variable flow rate by controlling the displacement of the hydrostatic pump. The relief valve serves as a safety valve and the system pressure is mainly determined by the electrical load. Therefore, the hydrostatic power source can simulate the fluctuant renewable energy supplied to the hydrostatic-driven electric generator as shown in Figure 1. The filter is used to ensure that the hydraulic oil flowing into the prototype has a high level of cleanliness. Although the generated electrical energy can be directly supplied to electrical loads, it cannot track the maximum power point of the fluctuant renewable energy source. Therefore, controllable power electronics are often employed to connect the generator terminals to electrical loads, batteries or grids. In the experimental platform, the generated energy is converted and supplied to batteries or direct current (DC) electrical loads with relatively low voltage through a diode rectifier and a buck converter $[35,36]$. Then the captured energy and the system pressure can be governed by the pulse width modulation (PWM) control signals input to the converter.

The main sensors and instruments involved in the experimental platform are introduced as follows. A pressure sensor and a flow meter are used to measure the pressure and the flow rate of the hydraulic oil flowing into the integrated hydrostatic-driven electric generator. A resolver and a signal modulator card are used to detect the rotational speed. Voltage and current sensors are employed to measure the generated voltages and currents. Although not in the schematic, there are also several temperature transducers installed in the prototype for thermal monitoring. In addition, a computer and data I/O cards are employed to acquire data and provide control signals to the buck converter and the variable-displacement pump. 


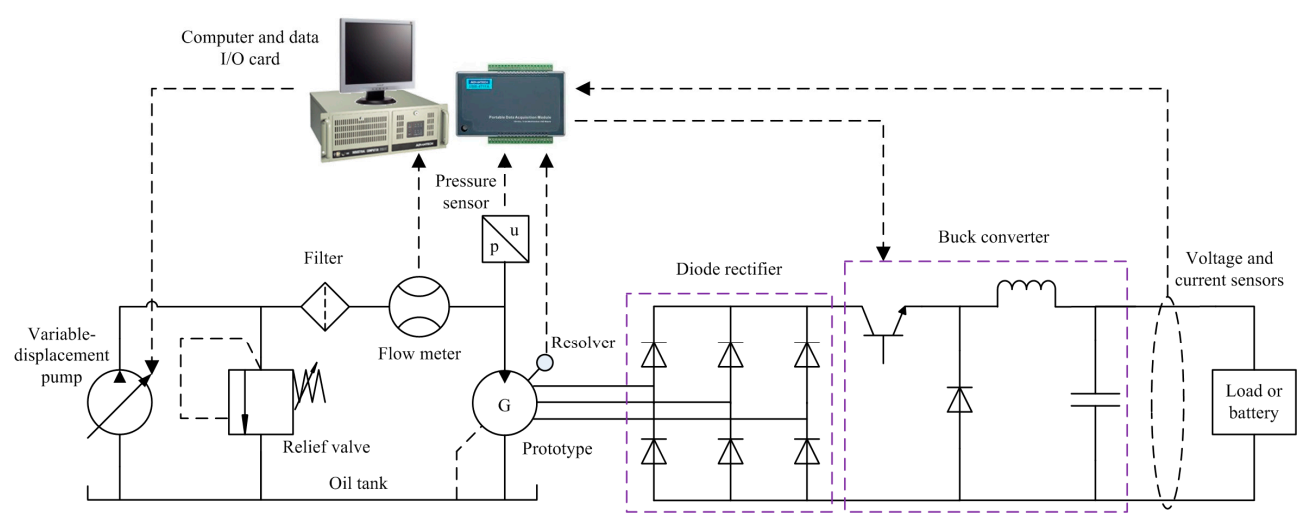

Figure 4. Experimental platform schematic for the integrated hydrostatic-driven electric generator.

\section{Energy Conversion Analysis}

\subsection{Losses in Energy Conversion}

The power losses of the integrated hydrostatic-driven electric generator with controllable load are specified from the input hydrostatic power to the output electrical power as shown in Figure 5, which mainly includes the leakage losses, the mechanical losses, the iron losses, the copper losses, and the losses of power electronics.

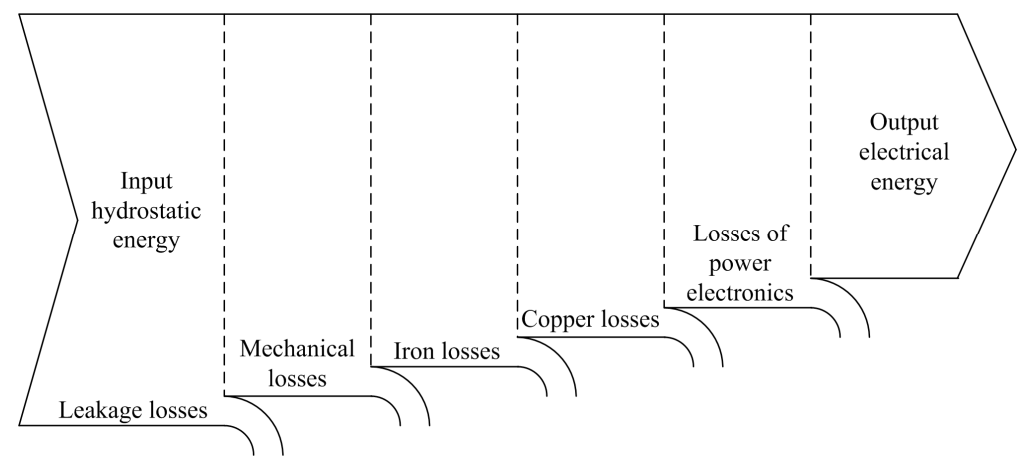

Figure 5. Power losses from the input hydrostatic power to the output electrical power.

The input hydrostatic power and the output electrical power can be expressed, respectively, as:

$$
\begin{gathered}
P_{i}=Q_{i}\left(p_{s}-p_{0}\right) \\
p_{0}=U_{d} I_{d}
\end{gathered}
$$

where $Q_{i}$ is the input flow rate of hydraulic oil, $p_{s}$ and $p_{0}$ are the oil pressures in the input and output ports, $U_{d}$ and $I_{d}$ are the voltage, and the current consumed on the DC electrical load. As the return oil line is connected to the oil tank, the relative pressure in the output port can be considered approximately as zero. Then the energy conversion efficiency is written as:

$$
\eta_{c}=p_{0} / p_{i} \times 100 \%
$$

The total power losses are equal to the difference between the input power and the output power. To evaluate their distributions in detail, some expressions are required for losses separation. Among them, the leakage losses can be calculated as [37]:

$$
P_{\text {leak }}=Q_{l}\left(p_{s}-p_{0}\right)=\left(Q_{i}-n_{r} D_{m}\right)\left(p_{s}-p_{0}\right)
$$


where $Q_{l}$ is the flow rate of the leakage oil, $n_{r}$ is the rotational speed of the machine rotor, and $D_{m}$ is the machine displacement. The expression of the copper losses is given as:

$$
P_{c o p p}=m I_{s}^{2} R_{s, 20}\left[1+\alpha_{20}\left(T_{s}-20\right)\right]
$$

where $m$ is the phase number, $I_{S}$ is the effective value of the fundamental current of the stator windings, $R_{s, 20}$ is the resistance of the stator windings at the temperature of 20 degrees, $\alpha_{20}$ is the temperature coefficient, and $T_{S}$ is the temperature of the stator windings. The iron losses in the stator can be expressed as [38]:

$$
P_{\text {iron }}=\left(k_{h} f_{e} B_{m}^{2}+k_{e x} f_{e}^{1.5} B_{m}^{1.5}+k_{e d} f_{e}^{2} B_{m}^{2}\right) V_{i}
$$

where $k_{h}$ is the hysteresis loss coefficient, $k_{e s}$ is the excess loss coefficient, $k_{e d}$ is the eddy current loss coefficient, $f_{e}$ is the electrical frequency, $B_{m}$ is the flux density in the stator iron core, and $V_{i}$ is the net volume of the stator iron core. The loss coefficients depending on iron material can be provided by the manufacturer. The losses of the power electronics include the power losses caused by the three-phase diode rectifier and the buck converter. Considering that the induced electromagnetic forces of the stator winding are sinusoidal, the power losses in the rectifier can be calculated as:

$$
P_{d}=\frac{4 \sqrt{2}}{\pi} I_{s} U_{f 0}
$$

where $U_{f 0}$ is the forward voltage of the diodes in the rectifier. It is assumed that the PWM control signals for the insulated gate bipolar transistor (IGBT) in the buck converter are with the modulation frequency $f_{m}$ and the on duty ratio $\beta$. To ensure that the converter always operates in continuous mode, the inductor and the capacitor in the converter are with values higher than the thresholds as given in [35]. The power losses in the buck converter are mainly caused by the resistance of the inductor and the wire, the switch losses of the IGBT, the conduction losses of the IGBT when on duty, and the conduction losses of the diode when off duty, of which the expression is given as [39]:

$$
P_{b}=I_{d}^{2} R_{c}+E_{s} f_{m}+\beta U_{f 1} I_{d}+(1-\beta) U_{f 2} I_{d}
$$

where $R_{c}$ is the resistance of the inductor and the wire, $E_{s}$ is the switching energy losses per modulation period, $U_{f 1}$ is the forward voltage of the IGBT, and $U_{f 2}$ is the forward voltage of the diode in the converter. Then the losses of the power electronics can be expressed as:

$$
P_{\text {elec }}=P_{d}+P_{b}
$$

According to Equations (4)-(9), the leakage losses, the copper losses, the iron losses, and the losses of the power electronics can be acquired directly by using design parameters and test data. However, it is difficult to evaluate the mechanical losses which are strongly dependent on the lubrication state of the frictional pairs in the studied machine. Herein an indirect approach is utilized to separate the mechanical losses approximately from the total losses with the following expression:

$$
P_{\text {mech }}=P_{i}-P_{o}-P_{\text {leak }}-P_{\text {copp }}-P_{\text {iron }}-P_{\text {elec }}
$$

It should be mentioned that there are additional power losses due to magnetic flux harmonics. Figure 6 shows the radial flux density in the stator-rotor gap and the flux distribution on the cross-section by using finite element analysis. It can be seen that the flux density waveform is close to a sinusoid which is beneficial to loss reduction [40] and the magnetic flux through the barrel is at a low level because of the self-shielding property of the Halbach permanent magnet array. Then based on the magnetic field analysis, the eddy-current losses in the permanent magnets are evaluated by using the calculation approach in [41]. It is found that they are ignorable compared with other types of power losses and the reasons are analyzed as follows. Firstly, the prototype operates at relatively 
low velocities and the electrical frequency is not high enough. Secondly, the harmonic components of the magnetic flux are not significant in comparison with the fundamental component. Thirdly, the permanent magnets are segmented both at circumferential and axial directions in prototype fabrication. Therefore, the additional power losses due to magnetic flux harmonics are not specified in this study.

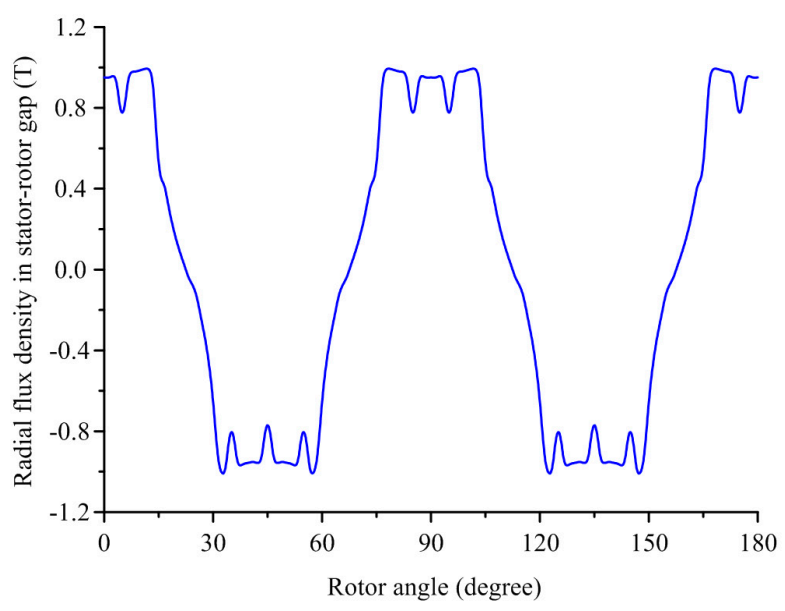

(a)

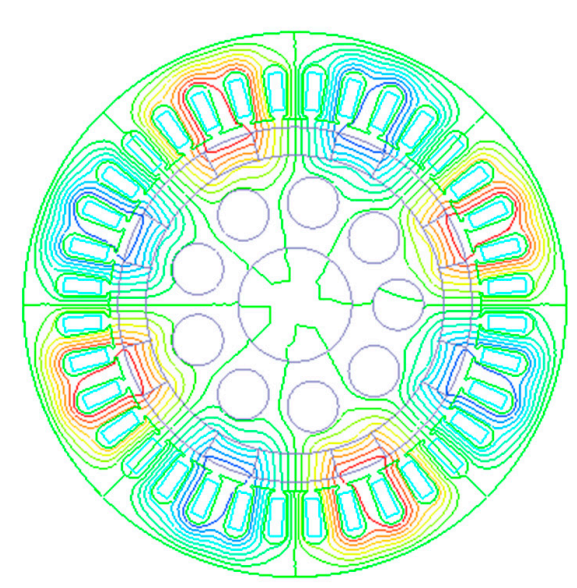

(b)

Figure 6. Finite element analysis on magnetic field. (a) Radial flux density in stator-rotor gap; and (b) flux distribution on cross section.

\subsection{Effect of Controllable Electrical Load}

This subsection analyzes the effect of the controllable electrical load on the integrated hydrostatic-driven electric generator. Figure 7 presents the equivalent electrical circuit of the studied machine and the power electronics. In this study, the output terminals of the buck converter are connected to a resistance, which makes the control strategy relatively simple. In future research with respect to charging a battery, a complex control strategy is required because of the constraints caused by the state of charge, voltage limit, as well as other parameters of the battery. Some denotations are explained as follows: $E_{S}$ is the induced electromagnetic force of the stator windings, $R_{S}$ and $L_{S}$ are the resistance and the inductance of the stator windings, $U_{s}$ and $I_{s}$ are the voltage and the current output by the stator windings, $U_{d 1}$ and $I_{d 1}$ are the voltage and the current output by the rectifier, and $R_{l}$ is the load resistance.

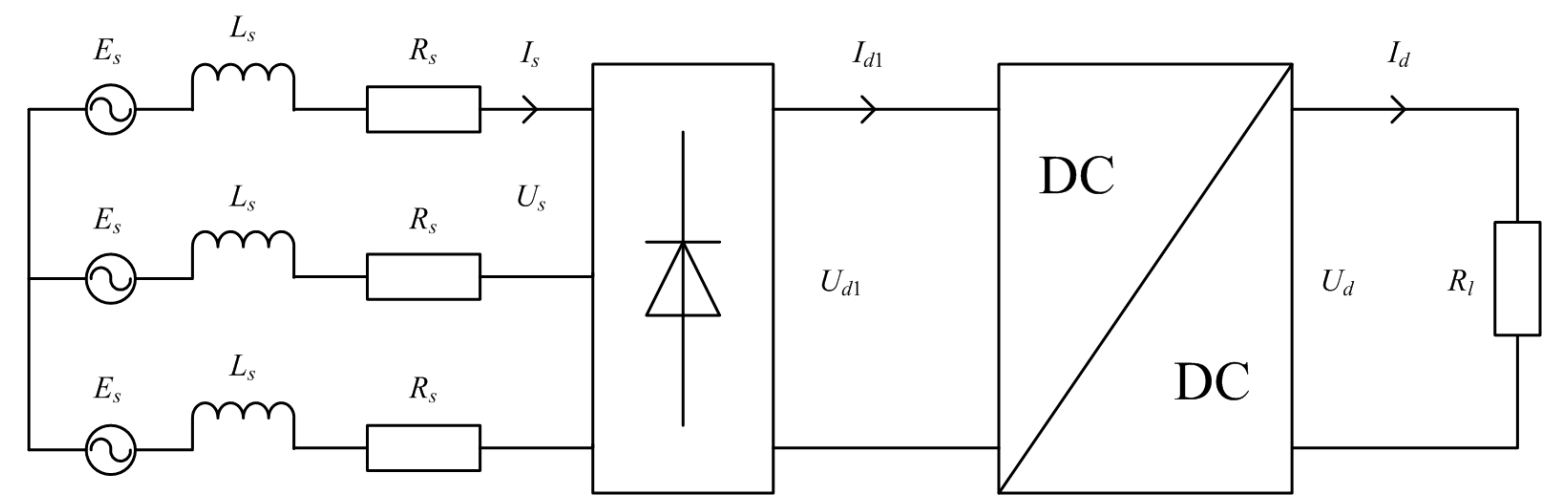

Figure 7. Equivalent electrical circuit of the studied machine and the power electronics.

Neglecting power losses in the buck converter, the following expressions can be given when the converter operates in continuous mode:

$$
U_{d}=\beta U_{d 1}
$$




$$
U_{d 1} I_{d 1}=U_{d} I_{d}
$$

Thus, the equivalent effect of the load resistance on the rectifier is calculated as:

$$
R_{l 1}=\frac{U_{d 1}}{I_{d 1}}=\frac{1}{\beta^{2}} \frac{U_{d}}{I_{d}}=\frac{R_{l}}{\beta^{2}}
$$

For the diode rectifier, it can be reasonably assumed that the phase angle between the input voltage and current is approximately equal to zero, for the equivalent load resistance is much larger than the reactance caused by the winding inductance. Then the following expressions can be given [42]:

$$
\begin{gathered}
U_{d 1}=\frac{3 \sqrt{6}}{\pi} U_{s} \\
3 U_{s} I_{s}=U_{d 1} I_{d 1}
\end{gathered}
$$

Similar, the equivalent effect of the load resistance on the generator is calculated as:

$$
R_{l 2}=\frac{U_{s}}{I_{s}}=\frac{\pi^{2}}{18} \frac{U_{d 1}}{I_{d 1}}=\frac{\pi^{2} R_{l}}{18 \beta^{2}}
$$

According to electrical circuit theory, the magnitude of the fundamental component of the stator current can be expressed as:

$$
I_{s}=\frac{E_{s}}{\sqrt{\left(R_{s}+R_{l 2}\right)^{2}+\left(2 \pi f_{e} L_{s}\right)^{2}}}
$$

and the load current can be calculated as:

$$
I_{d}=\frac{\pi E_{s}}{\sqrt{6 \beta\left[\left(R_{s}+R_{l 2}\right)^{2}+\left(2 \pi f_{e} L_{s}\right)^{2}\right]}}
$$

\subsection{Cooling and Temperature Rise}

Due to the integrated structure, the studied machine is prone to high temperature rise which has a strong effect on reliability and lifetime, so how to achieve effective heat dissipation is an important problem to solve.

Under natural cooling conditions, the generated heat is mainly transferred out through the cage surface and the input hydraulic oil. The hydraulic oil can be regarded as the coolant, for it usually gets cooled in the oil tank and has a lower temperature than the inner machine. However, its cooling effectiveness is limited by the two following factors. Firstly, most of the input hydraulic oil is circulated in the rotor and discharged through the output port. It cannot take heat away efficiently because of the small convection area. Secondly, although there is hydraulic oil leaked into the cage inner and discharged through the drain ports, the leakage flow rate is not considerable. Therefore, the studied machine in the case of natural cooling may have a high temperature rise and inhomogeneous distribution.

An oil-forced cooling approach is proposed for the integrated hydrostatic-driven electric generator, as shown in Figure 8. Different from the natural cooling approach where the hydraulic oil is just released through the output port, the oil-forced cooling approach connects the output port to one drain port and releases the hydraulic oil through another drain port. Since the two drain ports are located at the two ends of the studied machine, sufficient liquid convection can be realized when the hydraulic oil flushes through the machine inner. The oil-forced cooling approach has two advantages, one of which is that the convection area of the input hydraulic oil is enlarged significantly, and the other is that no additional pumping system for coolant is required. 


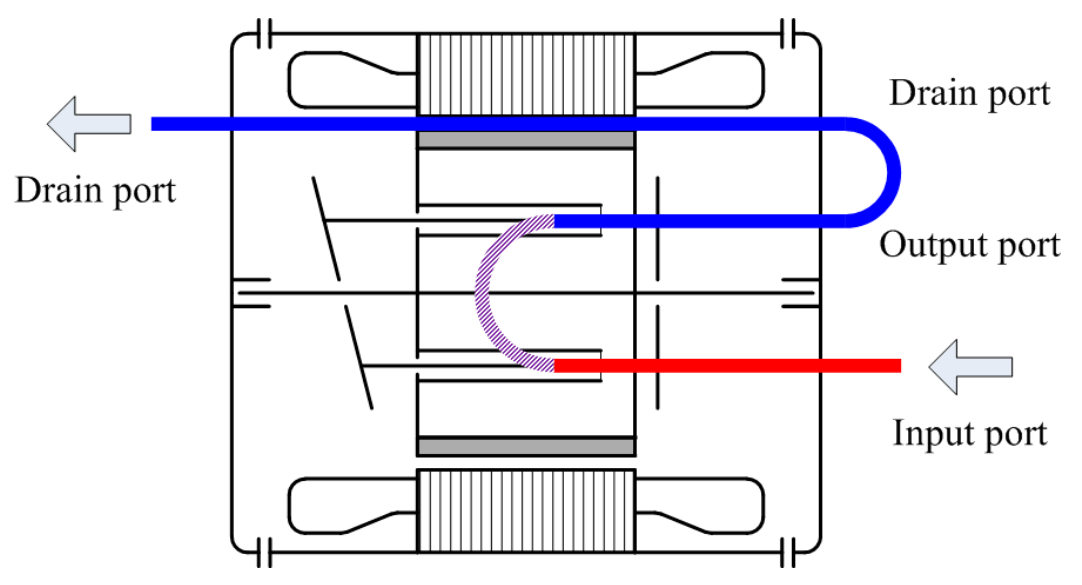

Figure 8. Schematic of the oil-forced cooling approach for the studied machine.

It can be deduced that the temperature distribution of the studied machine with the oil-forced cooling approach is much more homogeneous than the natural cooling approach. Thus, the average temperature rise can be calculated based on heat balance. Assuming that the machine heat is totally transferred by the input hydraulic oil, the approximate estimation of the average temperature rise is given as [43]:

$$
T_{r}=\frac{P_{i}-P_{o}}{c \rho Q_{i}}
$$

where $c$ and $\rho$ are the specific heat capacity and the mass density of hydraulic oil, respectively.

\section{Experiments and Results}

Firstly, the line-to-line induced electromagnetic forces of the prototype with different rotational speeds are measured under no-load conditions, as shown in Figure 9. It can be seen that the induced electromagnetic force is proportional to the rotational speed, and the slope is about $0.148 \mathrm{~V} / \mathrm{rpm}$, which is a quantity related with the permanent magnetic flux.

Then a series of experiments with different operating velocities and PWM signals in which the duty ratios vary from 0.0 to 1.0 are implemented under loaded conditions. The PWM signals are generated by using QPID card produced by Quanser (Markham, ON, Canada) and supplied to the IGBT, model number FF450R12ME4 produced by Infineon (Neubiberg, Bavaria, Germany), in the converter. Figure 10 shows the comparison between the measured and the calculated currents when the load resistance is equal to $25 \Omega$. It can be observed that the calculated results are in accordance with the experimental results in general, and there are also some errors which may be caused by the neglected power losses in Equation (18), as well as environmental uncertainty. Therefore, the load current can be effectively controlled by the PWM signal input to the buck converter, and the control range increases with the rotational speed. Simultaneously, the input hydrostatic pressure also produces corresponding variations as shown in Figure 11, which means the energy extracted from the energy source is adjustable. Thus, it is feasible to realize maximum power point tracking by adapting the input hydrostatic pressure to the optimal value. 


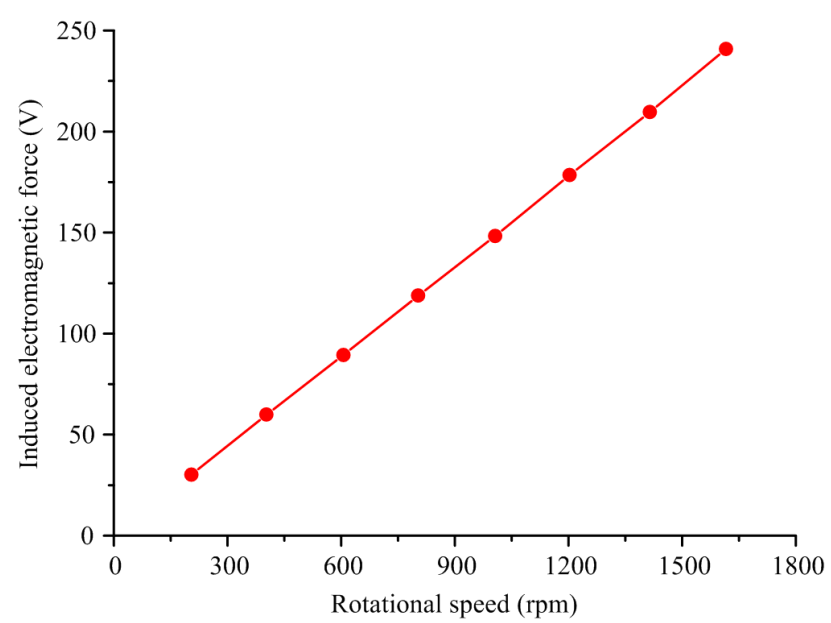

Figure 9. Induced electromagnetic force of the prototype varying with rotational speed.

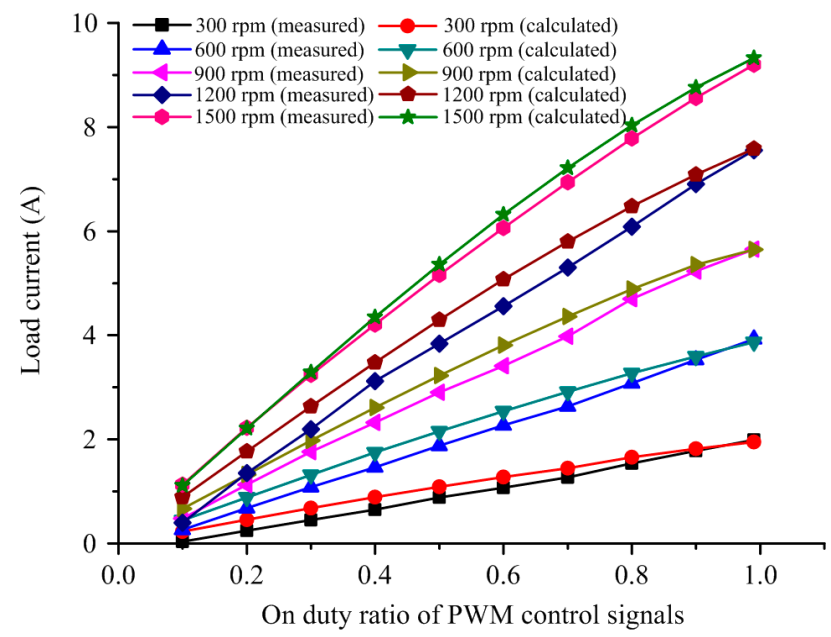

Figure 10. Measured and calculated load currents varying with rotational speed and on the duty ratio of the PWM control signals.

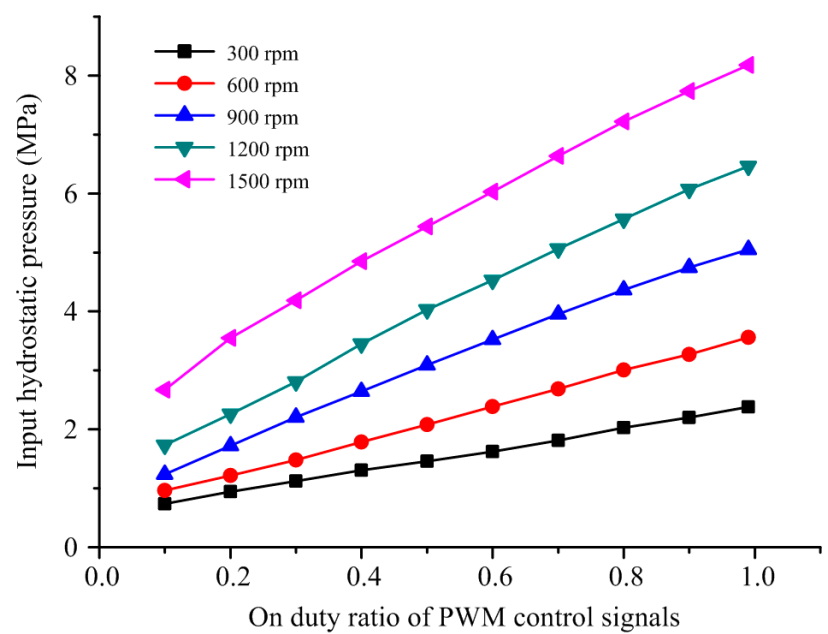

Figure 11. Experimental results of input hydrostatic pressure varying with rotational speed and on the duty ratio of the PWM control signals. 
Figure 12 presents the experimental results of the total energy conversion efficiency varying with the rotational speed and the on duty ratio of the PWM control signals. It can be seen that the overall efficiency increases with the on duty ratio and the maximum quantity is about $75 \%$. The effect of the rotational speed on the efficiency is not significant, except that the efficiency at the rotational speed of $300 \mathrm{rpm}$ is relatively lower. To further evaluate the power losses distribution, the aforementioned approach for losses separation is implemented by combining analytical calculation and measured data, and Table 2 presents the power loss distribution of the studied machine when the buck converter is on full duty. Figure 13 shows the comparison between the different types of the power losses of the studied machine. Since the prototype operates at relatively low pressure, the power losses due to the leakage flow are ignorable. It can also be noticed from the data that the copper losses and the mechanical losses constitute the most of the total power losses. Moreover, the percentage of the mechanical losses increases with the rotational speed while the copper losses behave oppositely. Thus, further efficiency optimization should concentrate on the reduction of the mechanical losses.

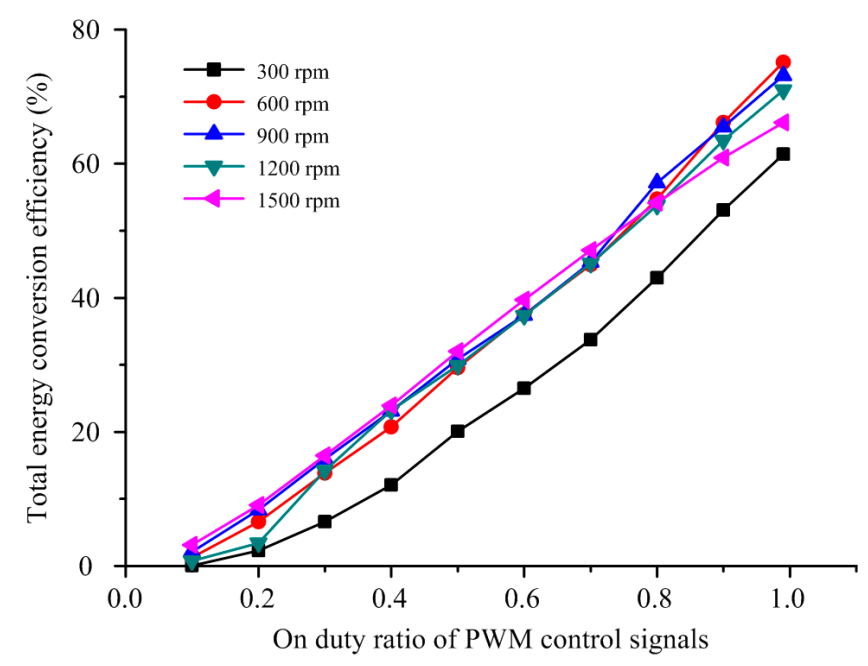

Figure 12. Experimental results of total energy conversion efficiency varying with rotational speed and on the duty ratio of PWM control signals.

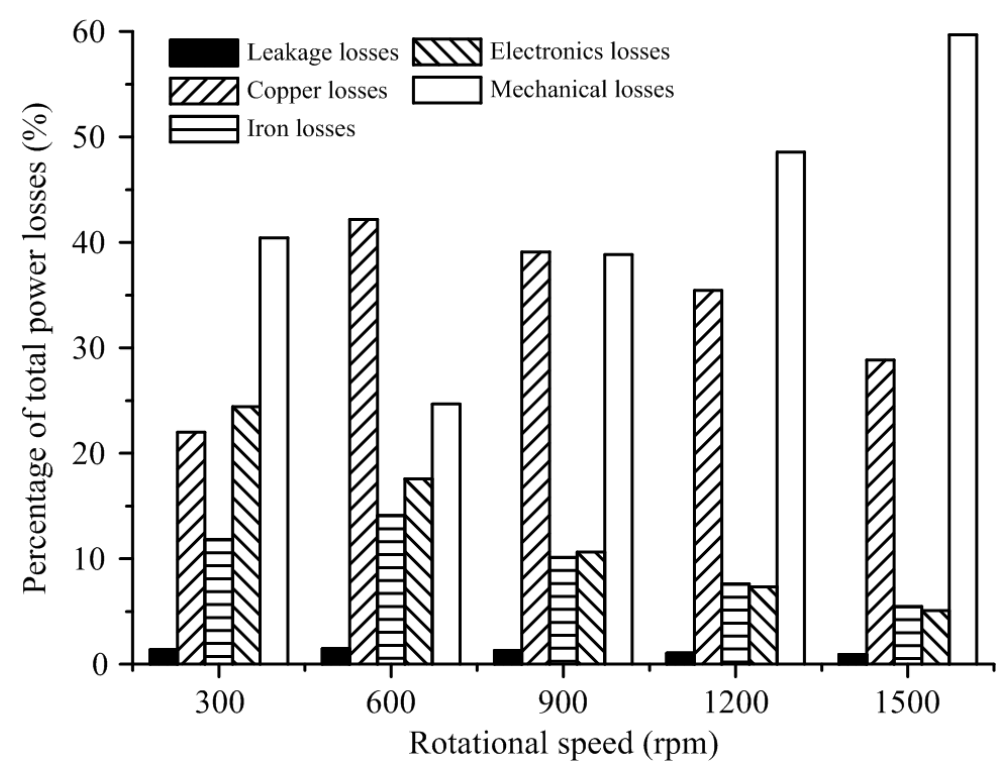

Figure 13. Comparison between different types of power losses of the studied machine. 
Table 2. Power loss distribution of the studied machine when the buck converter is on full duty.

\begin{tabular}{ccccccccc}
\hline $\begin{array}{c}\text { Rotational } \\
\text { Speed }\end{array}$ & $\begin{array}{c}\text { Input } \\
\text { Power }\end{array}$ & $\begin{array}{c}\text { Output } \\
\text { Power }\end{array}$ & $\begin{array}{c}\text { Total } \\
\text { Losses }\end{array}$ & $\begin{array}{c}\text { Leakage } \\
\text { Losses }\end{array}$ & $\begin{array}{c}\text { Copper } \\
\text { Losses }\end{array}$ & $\begin{array}{c}\text { Iron } \\
\text { Losses }\end{array}$ & $\begin{array}{c}\text { Losses of Power } \\
\text { Electronics }\end{array}$ & $\begin{array}{c}\text { Mechanical } \\
\text { Losses }\end{array}$ \\
\hline rpm & W & W & W & W & W & W & W & W \\
\hline 300 & 161 & 99 & 62 & 1 & 14 & 7 & 15 & 25 \\
600 & 513 & 386 & 128 & 2 & 54 & 18 & 22 & 31 \\
900 & 1092 & 799 & 293 & 4 & 115 & 30 & 31 & 114 \\
1200 & 2009 & 1426 & 583 & 6 & 207 & 44 & 43 & 283 \\
1500 & 3200 & 2116 & 1084 & 10 & 313 & 59 & 55 & 647 \\
\hline
\end{tabular}

Finally, the temperature rises of the studied machine under different cooling conditions are experimentally evaluated. Figure 14 shows the temperature measuring points where PT100 sensors are applied. It can be observed that plug-type sensors are adopted to detect the temperature of liquids, including the hydraulic oil in the input, output, and drain ports, and paste-type sensors are adopted to detect the temperature of solids including the cage and the stator.

Figure 15 presents the temperature variations of the measure points when the prototype is operated at the rotational speed of $1500 \mathrm{rpm}$ and the output power of $2.5 \mathrm{~kW}$. From the figure, some conclusions can be summarized as follows. In the natural cooling approach, the highest temperature point lies in the stator and its temperature rise reaches about 60 degrees. The temperatures of the input port and the output port are almost constant and equal to each other. In the oil-forced cooling approach, the highest temperature point lies in the cage and its temperature rise is less than four degrees. It is apparent the cooling performance of the oil-forced cooling is much improved in comparison with the natural cooling. The temperature difference between the input port and the final released port is about two degrees. According to Equation (19), the estimated temperature rise is 1.75 degrees, which is close to the experimental result.

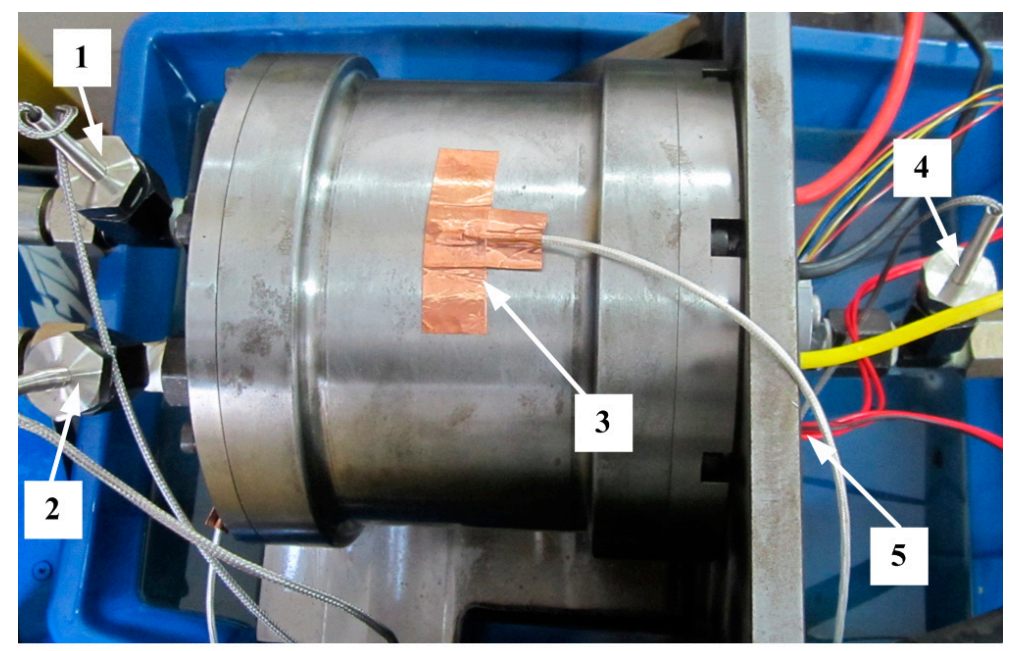

1. Input port. 2. Output port. 3. Cage. 4. Drain port. 5. Stator windings.

Figure 14. Temperature measuring points of the studied machine. 


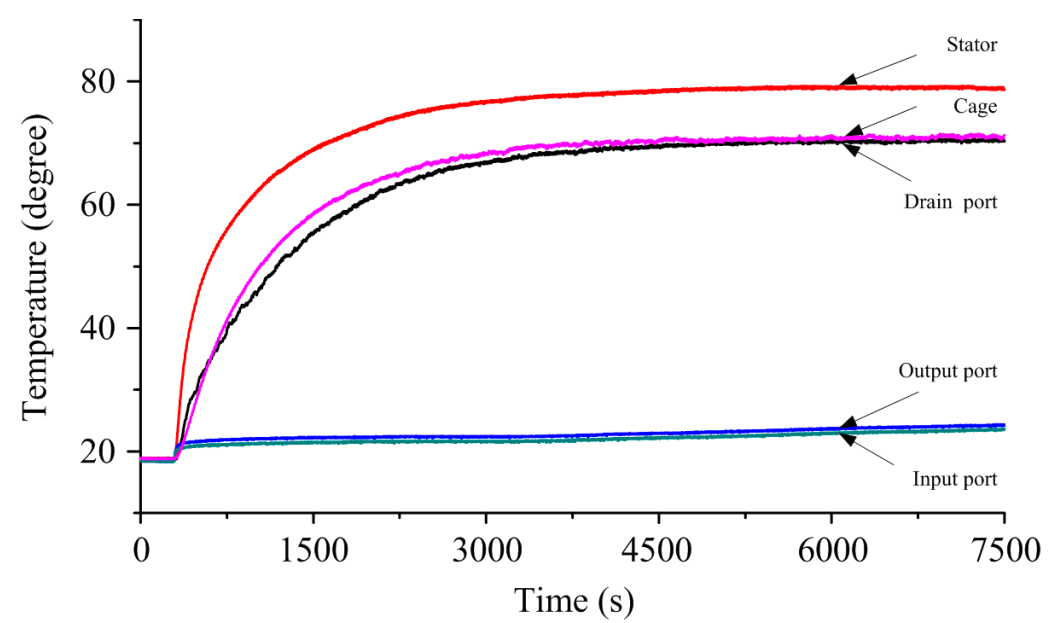

(a)

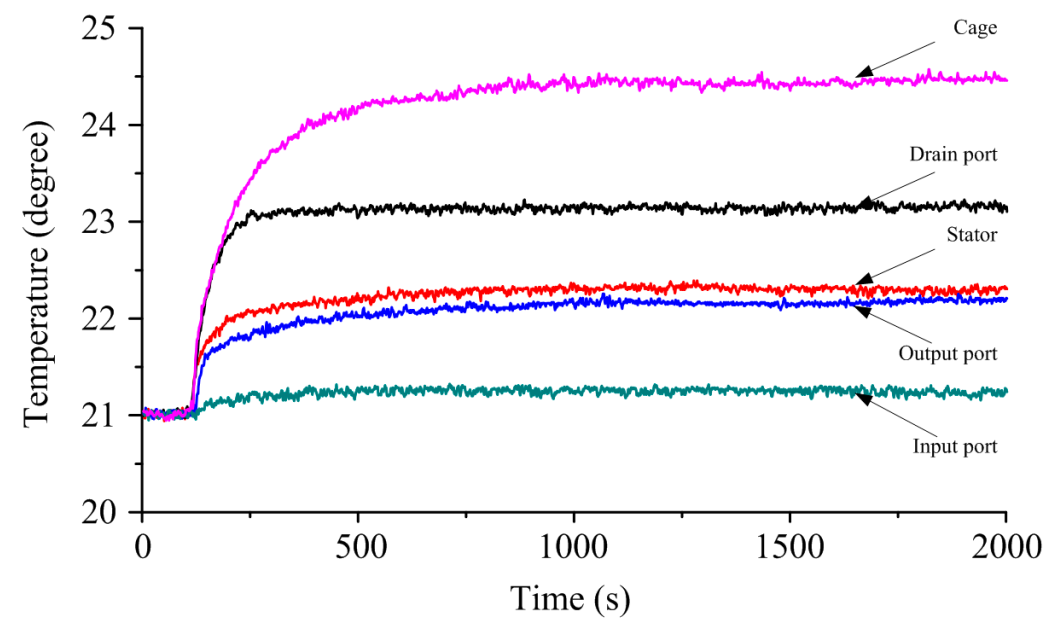

(b)

Figure 15. Comparison of the temperature rises of the studied machine: (a) natural cooling approach; (b) oil-forced cooling approach.

\section{Conclusions and Future Work}

This paper evaluates the performance of an integrated hydrostatic-driven electric generator with a controllable electrical load for renewable energy applications. The power losses in energy conversion, the converter effect, and the temperature rise are analytically investigated. An experimental platform for the prototype is set up by utilizing an adjustable hydrostatic power source, a controllable electrical load, and various sensors. Experiments of energy conversions between hydrostatic and electrical forms are implemented under different operating velocities and control signals. Power loss distributions are presented by combining measured data and analytical calculations. Cooling performances under both the natural and oil-forced cooling approaches are evaluated and the comparison shows that the temperature rise is much lower when the machine is cooled by hydraulic oil. The analytical and experimental results validate the energy conversion efficiency, steady controllability, and cooling capability of the integrated hydrostatic-driven electric generator.

The main contribution of this paper is to provide theoretical analysis and experimental data of the studied machine connected to a diode rectifier and a buck converter. Three positive points can be observed from the results. Firstly, the energy flow and the input hydrostatic pressure can be effectively governed by the buck converter, which provides the basis for maximum power point tracking. Secondly, the maximum energy conversion efficiency between hydrostatic and electrical 
forms reaches about $75 \%$. Thirdly, the proposed oil-forced cooling approach can significantly reduce the temperature rise of the integrated machine without additional pumping system.

However, there are also two deficiencies found in the study. Firstly, the mechanical losses take a high ratio of the total power losses and become barriers of efficiency improvement. This problem can be solved by replacing the standard hydrostatic parts with specially-developed ones. Secondly, this paper only focuses on the steady energy conversion of the studied machine with different control signals and dynamic control strategy is not involved. In future work, the efficiency optimization of the studied machine and the dynamic control for charging a battery will be further investigated.

Acknowledgments: This work supported by the National Natural Science Foundation of China (Grant No. 51405147), the Natural Science Foundation of Hunan Province, China (Grant No. 2015JJ3041), and the Fundamental Research Funds for the Central Universities.

Author Contributions: Tao Wang performed the system analysis, conceived and designed the experiments, performed the experiments, and wrote the paper; and He Wang performed the experiments and analyzed the data.

Conflicts of Interest: The authors declare no conflict of interest.

\section{References}

1. Ellabban, O.; Abu-Rub, H.; Blaabjerg, F. Renewable energy resources: Current status, future prospects and their enabling technology. Renew. Sustain. Energy Rev. 2014, 39, 748-764. [CrossRef]

2. Izadian, A.; Hamzehlouia, S.; Deldar, M.; Anwar, S. A hydraulic wind power transfer system: Operation and modeling. IEEE Trans. Sustain. Energy 2014, 5, 457-465. [CrossRef]

3. Nikolić, V.; Sajjadi, S.; Petković, D.; Shamshirband, S.; Ćojbašić, Ž.; Por, L.Y. Design and state of art of innovative wind turbine systems. Renew. Sustain. Energy Rev. 2016, 61, 258-265. [CrossRef]

4. Skaare, B.; Hörnsten, B.; Nielsen, F.G. Modeling, simulation and control of a wind turbine with a hydraulic transmission system. Wind Energy 2013, 16, 1259-1276. [CrossRef]

5. Silva, P.; Giuffrida, A.; Fergnani, N.; Macchi, E.; Cantù, M.; Suffredini, R.; Schiavetti, M.; Gigliucci, G. Performance prediction of a multi-MW wind turbine adopting an advanced hydrostatic transmission. Energy 2014, 64, 450-461. [CrossRef]

6. Polinder, H.; Ferreira, J.A.; Jensen, B.B.; Abrahamsen, A.B.; Atallah, K.; McMahon, R.A. Trends in wind turbine generator systems. IEEE J. Emerg. Sel. Top. Power Electron. 2013, 1, 174-185. [CrossRef]

7. Qin, C.; Innes-Wimsatt, E.; Loth, E. Hydraulic-electric hybrid wind turbines: Tower mass saving and energy storage capacity. Renew. Energy 2016, 99, 69-79. [CrossRef]

8. Dutta, R.; Wang, F.; Bohlmann, B.F.; Stelson, K.A. Analysis of short-term energy storage for midsize hydrostatic wind turbine. J. Dyn. Syst. Meas. Control 2014, 136, 011007. [CrossRef]

9. Fan, Y.; Mu, A.; Ma, T. Study on the application of energy storage system in offshore wind turbine with hydraulic transmission. Energy Convers. Manag. 2016, 110, 338-346. [CrossRef]

10. Lin, Y.; Tu, L.; Liu, H.; Li, W. Hybrid power transmission technology in a wind turbine generation system. IEEE/ASME Trans. Mechatron. 2015, 20, 1218-1225. [CrossRef]

11. Schulte, H.; Gauterin, E. Fault-tolerant control of wind turbines with hydrostatic transmission using Takagi-Sugeno and sliding mode techniques. Annu. Rev. Control 2015, 40, 82-92. [CrossRef]

12. Liu, H.; Lin, Y.; Shi, M.; Li, W.; Gu, H.; Xu, Q.; Tu, L. A novel hydraulic-mechanical hybrid transmission in tidal current turbines. Renew. Energy 2015, 81, 31-42. [CrossRef]

13. Fan, Y.; Mu, A.; Ma, T. Modeling and control of a hybrid wind-tidal turbine with hydraulic accumulator. Energy 2016, 112, 188-199. [CrossRef]

14. Gaspar, J.F.; Kamarlouei, M.; Sinha, A.; Xu, H.; Calvário, M.; Faÿ, F.X.; Robles, E.; Soares, C.G. Speed control of oil-hydraulic power take-off system for oscillating body type wave energy converters. Renew. Energy 2016, 97, 769-783. [CrossRef]

15. António, F.D.O. Phase control through load control of oscillating-body wave energy converters with hydraulic PTO system. Ocean Eng. 2008, 35, 358-366. [CrossRef]

16. Drew, B.; Plummer, A.; Sahinkaya, M.N. A review of wave energy converter technology. Proc. Inst. Mech. Eng. Part A J. Power Energy 2009, 223, 887-902. [CrossRef] 
17. Cargo, C.J.; Hillis, A.J.; Plummer, A.R. Optimisation and control of a hydraulic power take-off unit for a wave energy converter in irregular waves. Proc. Inst. Mech. Eng. Part A J. Power Energy 2014, 228, 462-479. [CrossRef]

18. Lin, Y.; Bao, J.; Liu, H.; Li, W.; Tu, L.; Zhang, D. Review of hydraulic transmission technologies for wave power generation. Renew. Sustain. Energy Rev. 2015, 50, 194-203. [CrossRef]

19. Ahn, K.K.; Truong, D.Q.; Tien, H.H.; Yoon, J.I. An innovative design of wave energy converter. Renew. Energy 2012, 42, 186-194. [CrossRef]

20. Truong, D.Q.; Ahn, K.K. Development of a novel point absorber in heave for wave energy conversion. Renew. Energy 2014, 65, 183-191. [CrossRef]

21. Hansen, R.H.; Kramer, M.M.; Vidal, E. Discrete displacement hydraulic power take-off system for the Wavestar wave energy converter. Energies 2013, 6, 4001-4044. [CrossRef]

22. Penalba, M.; Sell, N.P.; Hillis, A.J.; Ringwood, J.V. Validating a wave-to-wire model for a wave energy converter-Part I: The Hydraulic Transmission System. Energies 2017, 10, 977. [CrossRef]

23. Penalba, M.; Cortajarena, J.A.; Ringwood, J.V. Validating a wave-to-wire model for a wave energy converter-Part II: The electrical system. Energies 2017, 10, 1002. [CrossRef]

24. Wang, T.; Wang, Q. Optimization design of a permanent magnet synchronous generator for a potential energy recovery system. IEEE Trans. Energy Convers. 2012, 27, 856-863. [CrossRef]

25. Wang, T.; Wang, Q. An energy-saving pressure-compensated hydraulic system with electrical approach. IEEE/ASME Trans. Mechatron. 2014, 19, 570-578. [CrossRef]

26. Li, C.; Zhu, R.; Liang, M.; Yang, S. Integration of shock absorption and energy harvesting using a hydraulic rectifier. J. Sound Vib. 2014, 333, 3904-3916. [CrossRef]

27. Wang, R.; Gu, F.; Cattley, R.; Ball, A.D. Modelling, testing and analysis of a regenerative hydraulic shock absorber system. Energies 2016, 9, 386. [CrossRef]

28. Ponomarev, P.; Åman, R.; Handroos, H.; Immonen, P.; Pyrhönen, J.; Laurila, L. High power density integrated electro-hydraulic energy converter for heavy hybrid off-highway working vehicles. IET Electr. Syst. Transp. 2014, 4, 114-121. [CrossRef]

29. Ponomarev, P.; Polikarpova, M.; Heinikainen, O.; Pyrhonen, J. Design of integrated electro-hydraulic power unit for hybrid mobile working machines. In Proceedings of the 14th European Conference on Power Electronics and Applications, Birmingham, UK, 30 August-1 September 2011; pp. 1-10.

30. Wang, T.; Wang, Q. Coupling effects of a novel integrated electro-hydraulic energy conversion unit. Int. J. Appl. Electromagn. Mech. 2015, 47, 153-162. [CrossRef]

31. Ji, H.; Ding, D.; Wang, Z.; Wang, X.; Sun, L.; Hu, Q. Flow analysis and optimization of port-plate centrifugal pump in electric motor pump. J. Mech. Eng. 2009, 45, 199-205. [CrossRef]

32. Wang, T.; Zhou, Z. A compact hydrostatic-driven electric generator: Design, prototype, and experiment. IEEE/ASME Trans. Mechatron. 2016, 21, 1612-1619. [CrossRef]

33. Wang, T.; Wang, H.; Zhou, Z. Unbalanced magnetic torque in electrohydraulic energy conversion unit considering rotor axis deflection. IEEE Trans. Magn. 2016, 52, 1-6. [CrossRef]

34. Markovic, M.; Perriard, Y. Optimization design of a segmented Halbach permanent-magnet motor using an analytical model. IEEE Trans. Magn. 2009, 45, 2955-2960. [CrossRef]

35. Koutroulis, E.; Kalaitzakis, K. Design of a maximum power tracking system for wind-energy-conversion applications. IEEE Trans. Ind. Electron. 2006, 53, 486-494. [CrossRef]

36. Gurumurthy, S.R.; Agarwal, V.; Sharma, A. A novel dual-winding BLDC generator-buck converter combination for enhancement of the harvested energy from a flywheel. IEEE Trans. Ind. Electron. 2016, 63, 7563-7573. [CrossRef]

37. Wang, T.; Wang, Q. Efficiency analysis and evaluation of energy-saving pressure-compensated circuit for hybrid hydraulic excavator. Autom. Constr. 2014, 47, 62-68. [CrossRef]

38. Eriksson, S.; Bernhoff, H. Loss evaluation and design optimisation for direct driven permanent magnet synchronous generators for wind power. Appl. Energy 2011, 88, 265-271. [CrossRef]

39. Luo, F.L.; Ye, H. Energy factor and mathematical modelling for power DC/DC converters. IEE Proc. Electr. Power Appl. 2005, 152, 191-198. [CrossRef]

40. Hsiao, C.Y.; Yeh, S.N.; Hwang, J.C. Design of high performance permanent-magnet synchronous wind generators. Energies 2014, 7, 7105-7124. [CrossRef] 
41. Huang, W.Y.; Bettayeb, A.; Kaczmarek, R.; Vannier, J.C. Optimization of magnet segmentation for reduction of eddy-current losses in permanent magnet synchronous machine. IEEE Trans. Energy Convers. 2010, 25, 381-387. [CrossRef]

42. Chan, T.F.; Wang, W.; Lai, L.L. Analysis and performance of a permanent-magnet synchronous generator supplying an isolated load. IET Electr. Power Appl. 2010, 4, 169-176. [CrossRef]

43. Lu, Q.; Zhang, X.; Chen, Y.; Huang, X.; Ye, Y.; Zhu, Z.Q. Modeling and investigation of thermal characteristics of a water-cooled permanent-magnet linear motor. IEEE Trans. Ind. Appl. 2015, 51, 2086-2096. [CrossRef]

(C) 2017 by the authors. Licensee MDPI, Basel, Switzerland. This article is an open access article distributed under the terms and conditions of the Creative Commons Attribution (CC BY) license (http:/ / creativecommons.org/licenses/by/4.0/). 